\title{
ANÁLISE NUMÉRICA DE VIGAS DE CONCRETO ARMADO REFORÇADAS À FLEXÃO COM CFRP
}

\author{
FONTENELE CAVALCANTE, LIA \\ Estudante \\ Faculdade Ari de Sá \\ Ceará; Brasil \\ liafontenelec@hotmail.com
}

\author{
FERNANDES, JOÃO PAULO DE CASTRO \\ Estudante \\ Faculdade Ari de Sá \\ Ceará; Brasil \\ j.fernandes.ec@outlook.com
}

\author{
LIMA, ÉSIO MAGALHÃES FEITOSA \\ Professor Orientador \\ Faculdade Ari de Sá \\ Ceará; Brasil \\ esiomf@hotmail.com
}

\begin{abstract}
RESUMO
A utilização de fibra de carbono (CFRP) é caracterizada pela colagem das fibras em regiões específicas de uma estrutura. As principais características dessas fibras são a sua alta resistência mecânica; leveza; alta resistência à tração e grande rigidez. De frente as vantagens oferecidas pela utilização destas como elemento de reforço, este trabalho tem como objetivo realizar uma modelagem computacional através do método dos elementos finitos de quatro vigas de concreto armado onde três delas serão reforçadas com fibra de carbono de 3 tamanhos distintos e a viga restante não será reforçada para servir de referência. As vigas foram submetidas ao ensaio de Stuttgart e coladas na região de momento fletor positivo máximo, sendo ainda, todas as vigas modeladas em regime não linear. Os resultados mostraram que o reforço através da utilização de CFRP com fibras de 1,82x0,12m melhoraram o comportamento último da peça quando comparado ao das outras analisadas.
\end{abstract}

Palavras-chave: Modelagem Computacional, CFRP, Abaqus, Reforço Estrutural.

\section{ABSTRACT}

The use of carbon fiber (CFRP) is characterized by bonding the fibers to specific regions of a structure. The main characteristics of these fibers are their high mechanical strength; lightness; High tensile strength and great rigidity. Facing the advantages offered by the use of these as reinforcement element, this work aims to perform a computational modeling through the finite element method of four reinforced concrete beams where three of them will be reinforced with carbon fiber of 3 different sizes and the beam. The remainder will not be reinforced for reference. The beams were submitted to the Stuttgart test and glued in the region of maximum positive bending moment, being all the beams modeled in nonlinear regime. The results showed that the reinforcement using CFRP with $1.82 \times 0.12 \mathrm{~m}$ fibers improved the last behavior of the piece when compared to the others analyzed.

Keywords: Computational Modeling, CFRP, Abaqus, Structural Reinforcement.

\section{INTRODUÇÃO}

Nos últimos anos, os aspectos relacionados a prevenção e manutenção das estruturas de concreto armado têm sido cada vez mais estudadas devido ao surgimento de um número cada vez maior de manifestações patológicas, destacando principalmente as estruturas que estão mais expostas às ações agressivas do meio ambiente. A redução da durabilidade das estruturas está em questão visto a perda do desempenho estrutural, entretanto, dependendo da magnitude dessa perda devem ser analisadas as necessidades de reabilitação ou reforço (MENEGHETTI, 2007).

As técnicas de reabilitação de estruturas, por sua vez, vêm sofrendo modernizações de acordo com as necessidades de cada componente estrutural, uma vez que continuamente estão diminuindo tempos de execução em obra e procurando efetuar reabilitações ou reparos mais duradouros, com uma maior eficiência estrutural, visando também a redução dos custos (MENON,2008), que geralmente são muito altos em virtude da dificuldade de realização do serviço e da possível 
suspensão das atividades na estrutura (MENEGHETTI, 2007). Por exemplo, tradicionalmente, as técnicas mais utilizadas são as de reforço com a utilização de perfis laminados ou concreto armado, entretanto há algumas desvantagens nesses métodos, que estão relacionadas a dificuldade de aplicação do material, e na dificuldade de transporte dos materiais tendo em vista o peso, por exemplo, das chapas de aço.

Assim, técnicas modernizadas como a utilização de fibras sintéticas foram sendo desenvolvidas e amplamente utilizadas uma vez que dentre as propriedades das fibras destaca-se: o seu peso, o qual é $75 \%$ menor comparado ao peso do aço; alta resistência mecânica, sendo aproximadamente 9 vezes maior que a do aço considerando um mesmo módulo de elasticidade (LEAL, 2000 apud ARQUEZ, 2010). A utilização de polímeros reforçados com fibras de carbono (PRF), por sua vez, tem se destacado dentre a utilização de fibras sintéticas para o reforço estrutural, apresentando algumas vantagens em detrimento das técnicas tradicionais, como, a facilidade de aplicação, o aumento da resistência e ductibilidade e a possibilidade de manutenção das seções (MENEGHETTI, 2007).

O conhecimento e comportamento das estruturas a serem reforçadas estão inerentes a expressões matemáticas que necessitam ser mais bem entendidas e equacionadas, uma forma de realizar isso é através da análise matemática utilizando modelagens computacionais, mais propriamente, pelo método dos elementos finitos, o qual tem como base a discretização de um meio contínuo em pequenos elementos descritos por equações diferenciais, de forma que acabam mantendo as mesmas propriedades do meio original (LOTTI et. al., 2006).

Nesse contexto se insere a modelagem computacional a fim de facilitar o entendimento e a visualização dos efeitos de deslocamentos devido a ação das cargas, tal como a previsão de possíveis colapsos estruturais. Entretanto, apesar dos compósitos de fibra de carbono (PRFC) apresentarem diversas vantagens em relação aos métodos tradicionais de reforços ainda necessitam de estudos para possíveis melhorias no método.

\section{METODOLOGIA}

O presente estudo visa realizar uma modelagem computacional para verificar o comportamento de vigas de concreto armado reforçadas a flexãocom PRFC, localizados na região de momento fletor máximo. A fibra de carbono é disposta em 3 diferentes tamanhos, como observado na Figura 1.

a)

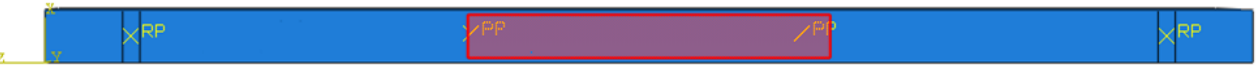

b)

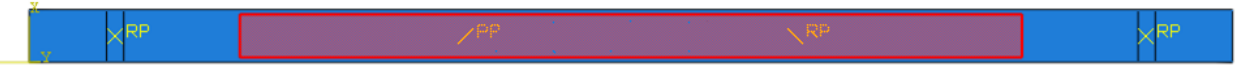

c)

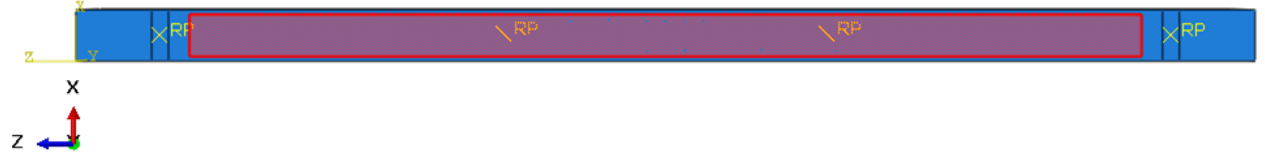

Figura 1: Reforços com PRFC em destace: a) PRFC com 0,84x0,1m; b) PRFC com 1,82x0,1m; c) PRFC com $2,26 \times 0,1 \mathrm{~m}$

A modelagem foi feita por meio do programa computacional @Abaqus-CAE Research V.14 através do método dos elementos finitos. Cabe aqui ressaltar que o modelo de viga analisada foi validada a partir do trabalho de Vieira, M. (2016). Assim, para o concreto armado convencional, foi feita uma viga de 2.800x245 mm, com perfil de $120 \times 245 \mathrm{~mm}$ o detalhamento da armação do concreto, por sua vez, é feito com 4 diâmetros distintos sendo a armadura negativa (N3) $\emptyset 6,30 \mathrm{~mm}$, armadura positiva (N1 e N2) de diâmetros $\varnothing 16 \mathrm{~mm}$ e $\emptyset 8 \mathrm{~mm}$ e estribos (N4) Ø5 mm. A representação grafica desta peça vode ser observada na Figura 2. 


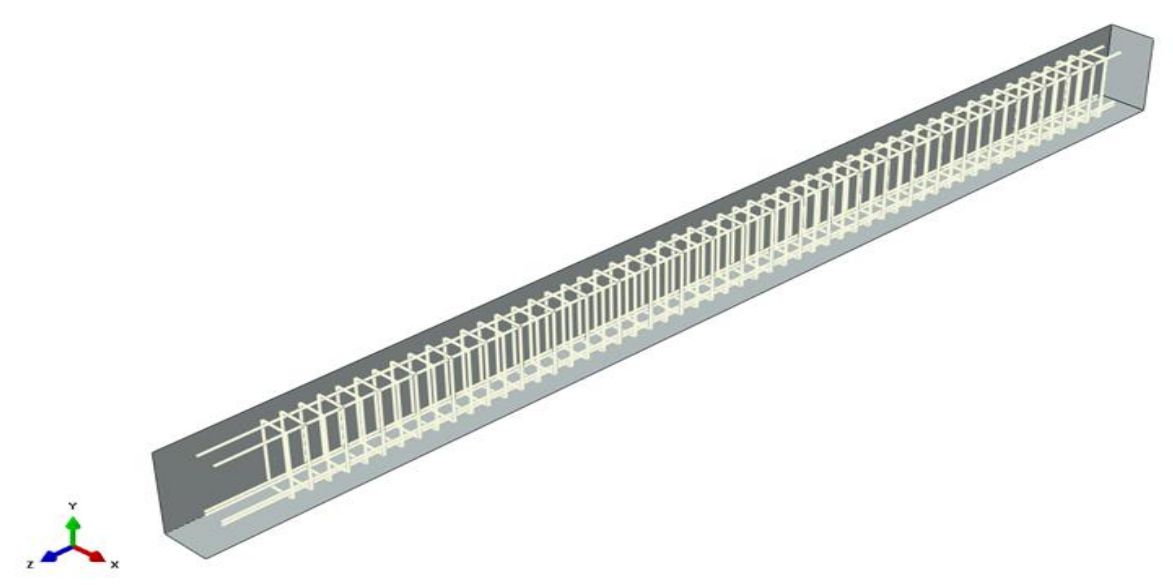

Figura 2: Representação gráfica da viga de refêrencia, com destaque para sua armadura.

Os materiais considerados para esta modelagem são apresentados na Tabela 1 abaixo.

Tabela 1. Propriedades físicas dos materiais

\begin{tabular}{|c|c|c|c|}
\hline & CONCRETO & AÇO & FIBRA DE CARBONO \\
\hline $\mathbf{E}$ & $30 \mathrm{GPa}$ & $200 \mathrm{GPa}$ & $230 \mathrm{GPa}$ \\
\hline $\mathbf{v}$ & 0.20 & 0.33 & \\
\hline
\end{tabular}

\subsection{Da Modelagem Computacional}

Para a concepção da viga, opta-se por simulá-la através do ensaio de Stutgart. A modelagem foi realizada em regime não linear para se obter uma melhor proximidade com resultados experimentais. Para consideração da não linearidade física dos materiais foram utilizadas diversas curvas tensão deformação. Para representação do concreto à compressão e tração foi utilizada a curva da norma européia CEB-FIP. Já para o aço, foi considerado um comportamento elastoplastico perfeito. A Figura 3 representa a modelagem computacional realizada.

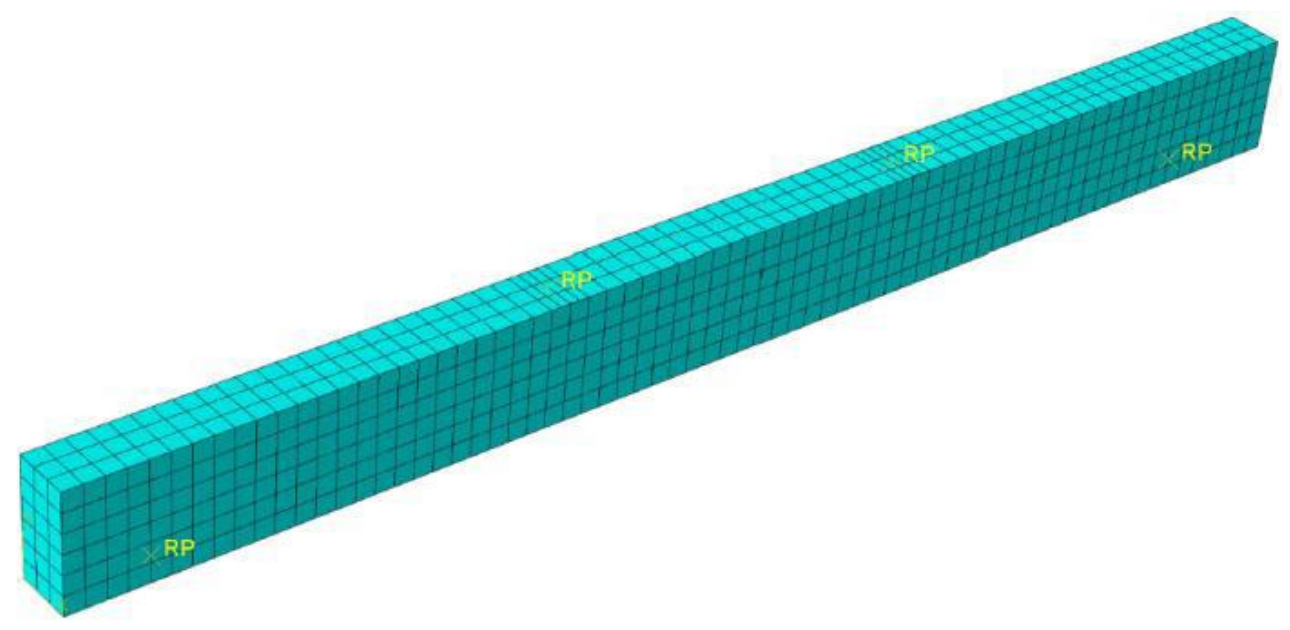

Figura 3: Modelagem Computacional da Viga de Concreto armado com PRFC.

Para fins de melhor comprenção dos resuldados obtidos as vigas foram classificadas conforme a Tabela 2, onde VR representa a viga de referencia, VA a viga reforçada com a $0,84 \mathrm{~m}$ de fibra de carbono, VB a viga reforçada com a 1,82 $\mathrm{m}$ de fibra de carbono e VC a viga reforçada com a 2,26 $\mathrm{m}$ de fibra de carbono. 
Tabela 2. Referências de vigas

\begin{tabular}{cc}
\hline REFERÊNCIA & DESCRIÇÃO \\
\hline VR & Viga Referencial sem reforço. \\
\hline VA & Viga com reforço de tamanho $0,84 \mathrm{x} 0,1 \mathrm{~m}$ \\
\hline VB & Viga com reforço de tamanho $1,82 \times 0,1 \mathrm{~m}$ \\
\hline VC & Viga com reforço de tamanho $2,26 \mathrm{x} 0,1 \mathrm{~m}$ \\
\hline
\end{tabular}

\section{RESULTADOS E DISCURSÕES}

Os resultados obtidos através da modelagem no programa Abaqus são apresentados a seguir. A metodologia de análise dos resultados consiste em comparar os dados das vigas reforçadas com os da viga de referência, bem como comparar dos dados das vigas reforçadas entre si. O gráfico carga-deslocamento, mais conhecido como caminho de equilíbrio, foi gerado para as três vigas modeladas. O eixo vertical do gráfico representa a carga total aplicada a peça, e o eixo horizontal representa o deslocamento vertical em um nó no meio do vão. A Figura 4 ilustra este fenômeno. A Tabela 1 demostra quais são as referências para cada viga.

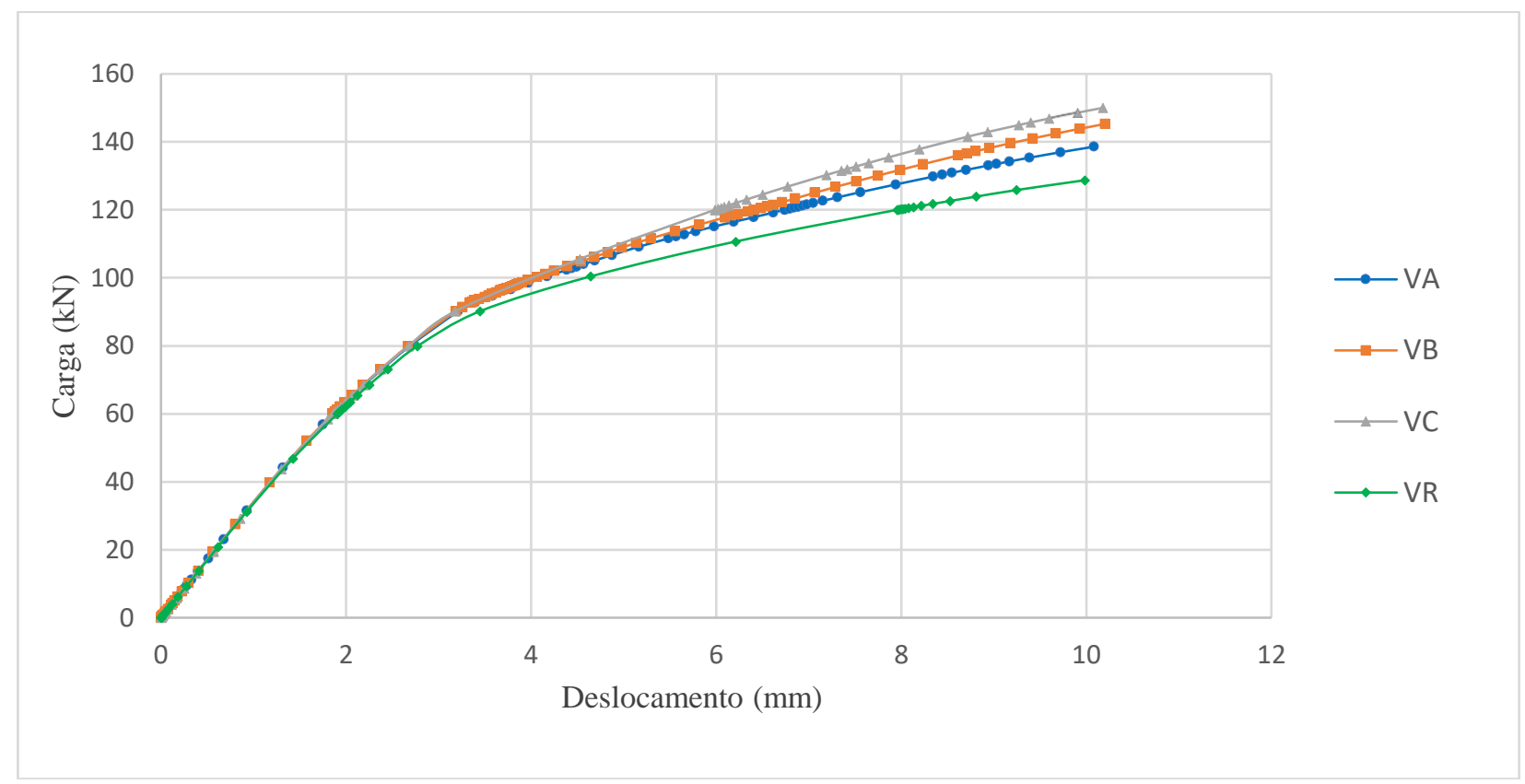

Figura 4: Caminho de equilíbrio das vigas modeladas

O caminho de equilíbrio mostrado na Figura 4 mostra um efeito bastante importante da peça. Quando o tamanho das fibras é alterada, a capacidade de carga da viga varia, isso pode ser verificado quando é avaliado os valores desta em função dos deslocamentos. Assim, percebe-se que todas as peças possuem um comportamento dúctil. Além disso, os deslocamentos últimos são bastante semelhantes quando comparadas as vigas VB e VC. Já para a VA que utiliza reforço de tamanho $0,84 \times 0,12 \mathrm{~m}$, a peça não teve grandes deslocamentos quando comparada a VR. Ainda na Figura 4, pode-se avaliar o nível de carga que cada peça atingiu, bem como a sua rigidez. Nota-se que a rigidez não variou no trecho linear para as quatro vigas, ou seja, antes de iniciar a plastificação dos materiais, mais especificamente do concreto, a fibra de carbono não atua como elemento de reforço, ou seja, não fornece rigidez ao sistema. Já no trecho não linear, nota-se que a rigidez da viga reforçada com fibras de 2,26x1,0 m (VC) é bastante superior à das outras três, obtendo como carga última $150,00 \mathrm{KN}$.

A Figura 5 ilustra o gráfico de variação das tensões nas fibras de carbono mais tracionadas em relação a carga aplicada. Ao analisar a Figura 5, nota-se que para um mesmo nível de carga, as tensões de tração na viga VA são superiores as tensões de tração na viga VB entretanto apesar de expressarem curvas muito semelhantes, a peça VB absorve maiores tensões quando submetida a um mesmo nível de carga. 


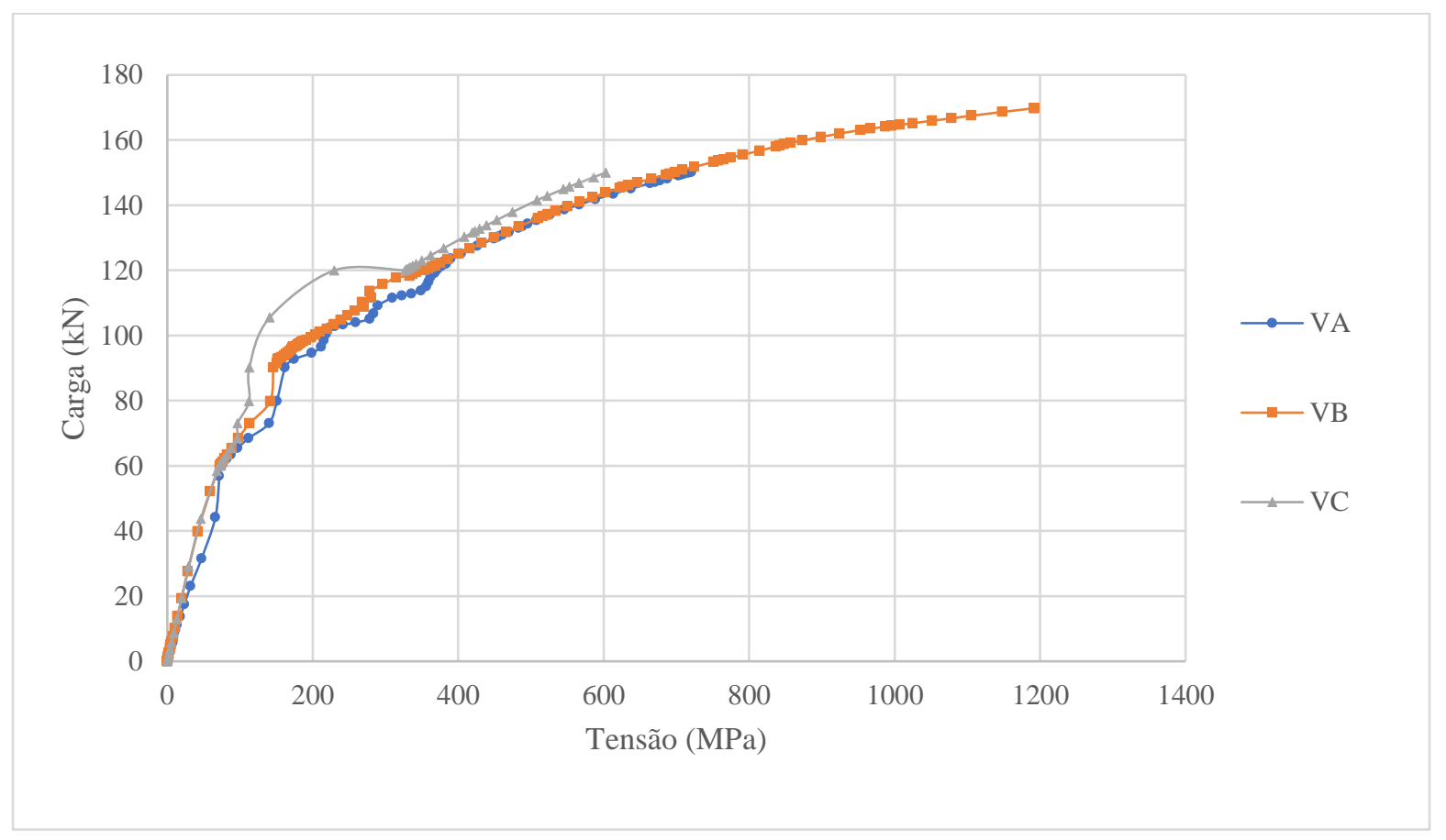

Figura 5: Variação das tensões de tração nas fibras em relação a carga aplicada

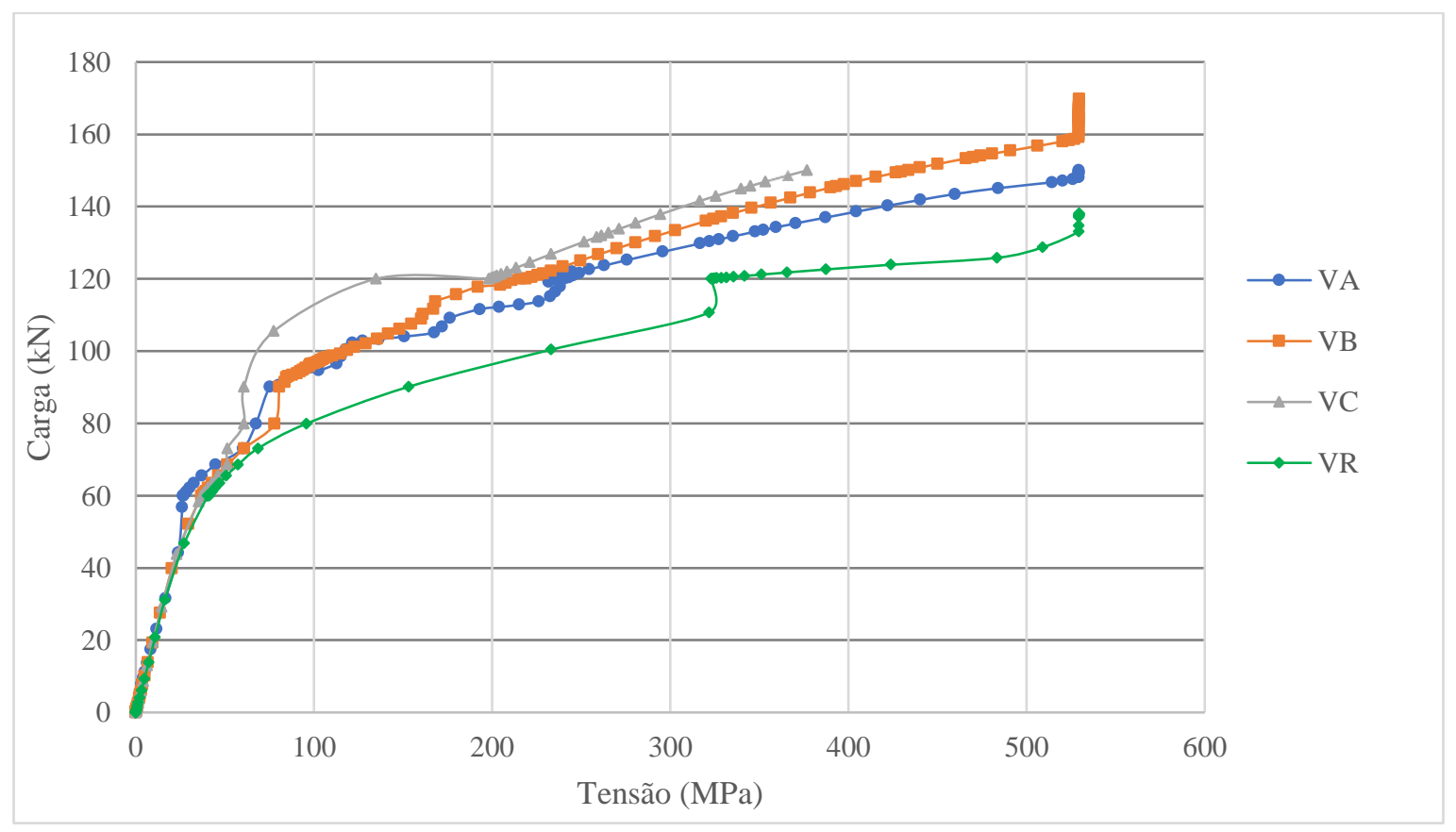

Figura 6: Tensões nas armaduras positivas

A Figura 6 ilustra a distribuição de tensões nas armaduras positivas em função da carga. Nota-se, nesta figura, que a peça referência (VR) possui maior tensão na armadura positiva do que todas as as vigas reforçadas para uma mesma carga, em contrapartida a peça VC possui um menor nível de tensão nas armaduras. Assim, de acordo com a Figura 7, percebe-se que há um aumento proporcional nas tensões da fibra e das armaduras até $530 \mathrm{Mpa}$, a partir desse ponto somente a fibra é tensionada, absorvendo parte das tensões de tração, e aliviando a carga transferida pra as armaduras. Esse fenômeno é observado em maior grau na peça VC. Já a VA alivia com menor intensidade as cargas transferidas para armadura, sendo esta última responsável por resistir aos maiores esforço de tração. A Figura 8 mostra o mapa de tensões no concreto das vigas. 


\section{СВРAT 2020

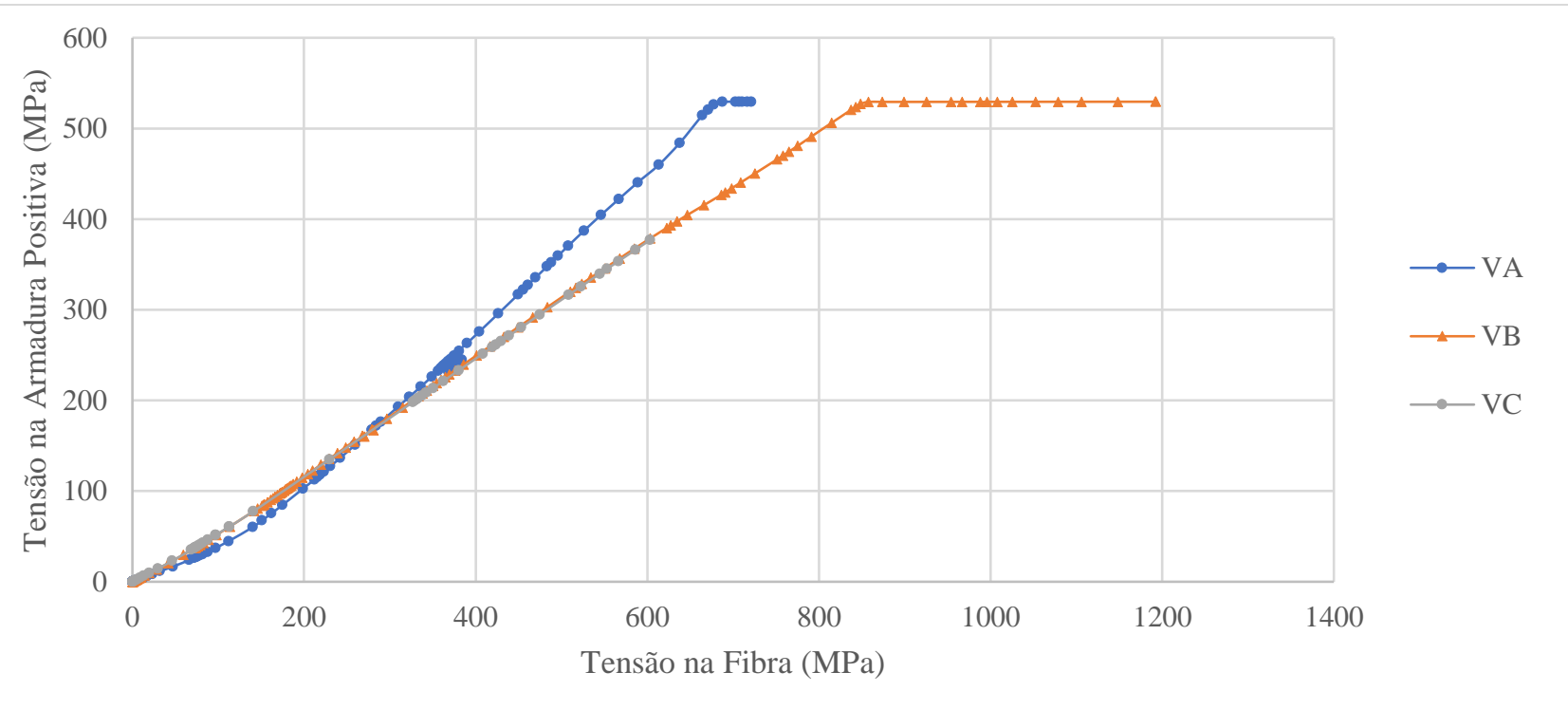

Figura 7: Tensões nas fibras e nas armaduras positivas

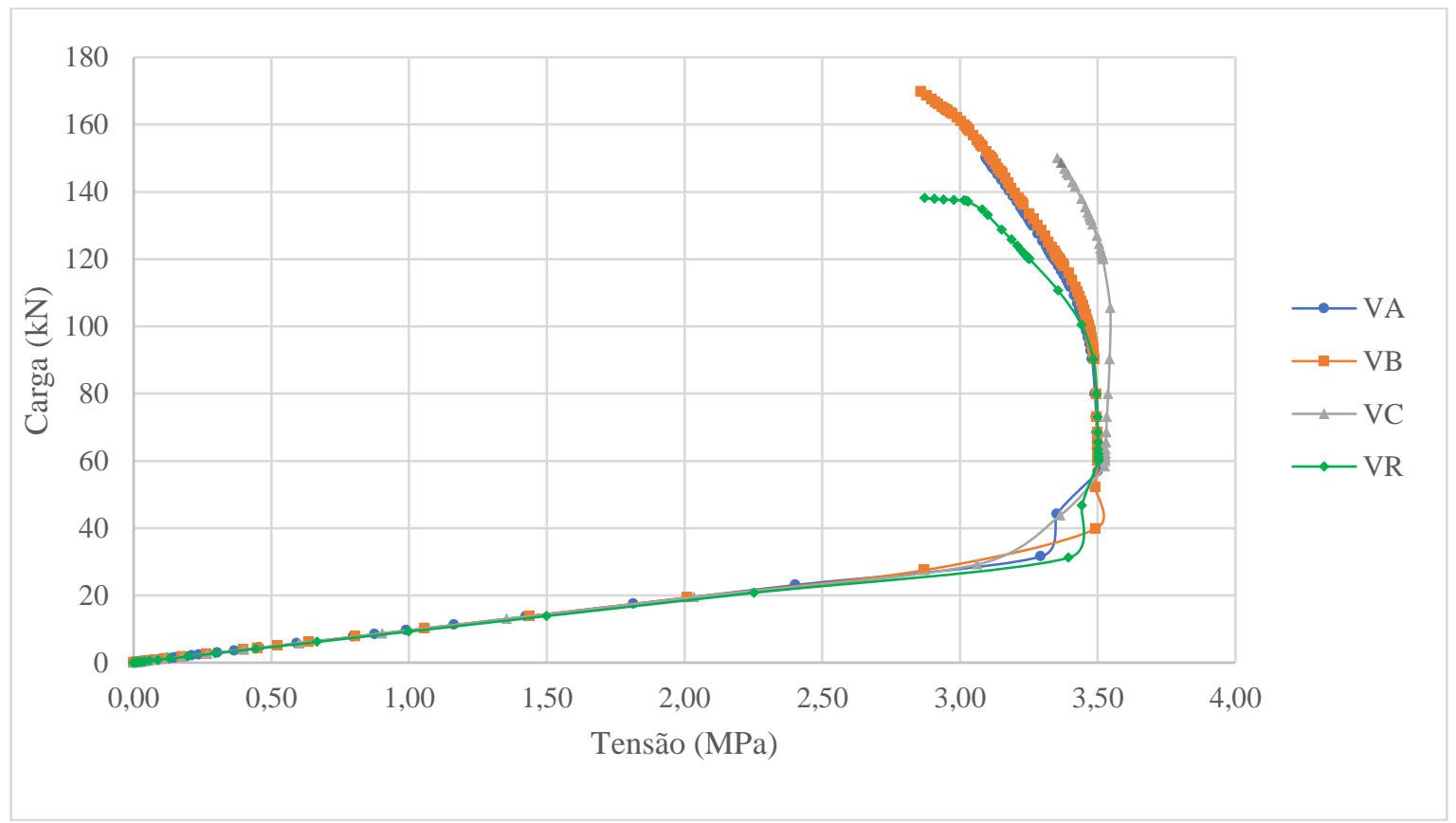

Figura 8: Campo de tensões de tração no concreto.

Avaliando a Figura 8, pode-se notar que as tensões de tração no maciço de concreto são bastante semelhantes antes de ocorrer fissuração, após esse momento, a viga VC, que é a viga com maior comprimento da fibra, apresenta um patamar de carga para um mesmo nível de tensão, enquanto as demais vigas, tendem ter as tensões reduzidas.

\section{CONSIDERAÇÕES FINAIS}

Das inúmeras técnicas e materiais existentes para o reforço de vigas, as fibras de carbono foram os utilizadas, por constituírem um material alternativo aos tradicionais e apresentarem várias vantagens, como por exemplo a leveza, facilidade de aplicação, o fato do peso da estrutura reforçada ser praticamente inalterado, introdução do confinamento desejado sem aumentar a secção transversal das peças estruturais, entre outros. Quanto às técnicas de reforço, a pesquisa 
foi direccionada para a aplicação de camadas da fibra na superfice da peça onde ocorre as maiores solicitações de esforços. Entretanto, a reduzida quantidade de trabalhos científicos que trabalham com modelagem computacional e aplicação de fibras de carbono dificultou a análise crítica e comparativa dos resultados obtidos neste trabalho.

Por fim, pode-se concluir que o presente trabalho alcançou os objetivos estipulados, uma vez que as peças estruturais foram modeladas e avaliadas conforme indicado. As vigas que possuíam fibras maiores comprimentos forneceram maior rigidez a peça, possibilitando a esta, atingir uma maior carga última quando comparada às outras vigas, além disso, notouse que a fissuração nesta peça é retardada quando comparada a viga de referência, assim como há uma absorção da carga atuante nas armaduras positivas por parte da fibra. A viga a qual possui tamanho intermediário se destacou quando se trata de esforços de tração, uma vez que apesar de expressarem curvas muito semelhantes, a peça VB mostra que suporta maiores tensões quando submetidas a maiores cargas, alcançando mais de $1.000 \mathrm{MPa}$. A viga sem reforço e a reforçada com fibras menores $(0,84 \times 0,12 \mathrm{~m})$ praticamente não tiveram diferenças significativas quando comparadas entre si. A única diferença notada foi em relação a carga última e tensão máxima.

\section{REFERÊNCIAS}

ARQUEZ, A.P. Aplicação de laminado de polímero reforçado com fibras de carbono (PRFC) inserido em substrato de microconcreto com fibras de aço para reforço à flexão de vigas de concreto armado. 2010. 242f. Dissertação (Mestrado em Engenharia de Estruturas) - Escola de Engenharia, Universidade de São Paulo, 2010.

LOTTI, R. S. et al. Aplicabilidade científica do método dos elementos finitos. Revista Dental Press de ortodontia e ortopedia facial, v. 11, n. 2, p. 35-43, 2006.

(http://www.scielo.br/pdf/dpress/v11n2/a06v11n2.pdf)

MENEGHETTI, L.C. Análise do comportamento à fadiga de vigas de concreto armado reforçadas com PRF de vidro, carbono e aramida. 2007. 277f. Dissertação (Pós-Graduação em Engenharia Civil) - Escola de Engenharias, Universidade Federal do Rio Grande do Sul, 2007.

MENON, N.V. Estudo experimental de sistemas de reforço ao cisalhamento em vigas de concreto armado utilizando-se polímero reforçado com fibras de carbono (PRFC). 2008. 332f. Dissertação (Pós-Graduação em Engenharia Civil) - Universidade Federal de Santa Catarina, 2008. 